\title{
COVERAGE OF SCIENCE AND TECHNOLOGY ON OPINION PAGES OF LEADING DAILIES
}

\author{
Muhammad Mujtaba Rashid \\ Department of Media Studies \\ Sindh Madressatul Islam University Karachi
}

\begin{abstract}
We live in a modern world which is full with a lot of inventions and techniques. Our lives are largely facilitated by scientific inventions. Media is also a byproduct of scientific inventions i.e. printing press, radio, television, internet etc. The connection of media and the society is of huge importance. Media is a mirror image of the society which represents the overall picture of society. Beside this the media educate and inform the people about certain realities and different spheres of society. In today's world we largely depend on science \& technology and also very much aware of the point that how crucial is the science in economical development of the country. Being an underdeveloped country we need to focus more on science $\&$ technology and for this our media has to play a decisive role of opinion maker. Through extensive coverage to science and technology sector we may be able to construct a scientific culture in our society which will resultantly be helpful to achieve the goal of knowledge economy. This study has examined the role of media specifically print media through measuring the frequency of coverage it give to science and technology on opinion pages. As Pakistan is a developing country and the majority of population generally understand national language so it is worth mentioning that the role of media is to ascertained through classification of Urdu and English print media. In this study we have chosen one year publications i.e. 360 editions of the year 2017 of two newspapers, one Urdu and one English to analyze the trend of media that which language gives more coverage to science and technology news, resultantly, it will be helpful for us to construct an appropriate opinion regarding media coverage of science and technology.
\end{abstract}

Keywords: Science and technology, coverage, print media, society, Pakistan.

1.rmujipak@yahoo.com 


\section{INTRODUCTION}

Today's world is entirely dependent on the scientific inventions. We use so many gadgets and equipment's in our daily life to perform our domestic activities without any hassle. Mostly the scientific inventions are from the western world and this is because of the reason that there is a scientific culture developed in those countries. What we really mean with scientific culture? Scientific culture is a set of principles and functions and a philosophy of truthfulness, sincerity, and continuous reflection, including how research worth is analyzed. Scientific inventions have made this world a global village where distance doesn't matter and whole world is connected with each other. Burke, et.al (1985) said that in modern world prosperity largely depends on scientific progression. All fields of life including, commerce, industries, defense, education, health, agriculture are equipped with sophisticated scientific and technological inventions which have not only made the progress faster but their socio-economic impacts are long-lasting. Science and technology has a leading impact on society which is increasing day by day. Now our life is completely changes, all segments and walks of life have radically changed. If we see ways of communication, our working styles and different ways for performing our work, our residences, what we wear, what we eat, how do we transport last but not the least the quality and extent of our lives, science has drastically changed the moral standards, ethical values and basic beliefs of mankind. From cultivation to elimination of our societal anxiety, science has proven to be a catalytic factor in bringing change. Our lives have become easier because of the progress of science. Now our education, health, ethics, sense of aesthetics and justice system are far better than past. Besides these tremendous changing factors, science has also made us able for our self destruction.

Pew Research Centre (1999) explained that the scientific and technological development in means of communication and transportation has benefitted the masses and largely praised by the public. The recent inventions have fascinated the young generations like social media, smart phones etc.

Wajeha (2012) elaborated that the scientific advancements and development is nonetheless a great human revolution which has influenced every segment of the society and sphere of life. A man of previous centuries could hardly think or imagine the life which we are actually living. Beside tremendous positive impacts of science on mankind, there are certain negative impacts too on the society.

\section{Media and the Society}

During past two decades the communication technology has developed at phenomenal speed and so many theories have been put up that how much these new means of communication will affect the humans and the society in which they live together.

Media is the reflection of society and being the opinion maker of the society, it is the vital responsibility of media to educate and inculcate awareness in the masses about certain issues of the society. As a fourth pillar of the state it is media's domain to build a nation with disseminating the information required to masses for their 
knowledge. Media reflects the society and reports what is happening in the society. The role of media in societal development is inevitable.

Pakistan is a developing country where majority of the population lives in rural areas. Due to low literacy rate and huge urban rural divide Pakistan lacks in the scientific education at higher level which results in low scientific development. Being a watchdog and opinion maker it is the vital responsibility of media to educate and inculcate awareness in the masses about certain issues of the society. For the well being of scientific and technological environment it is necessary that media should give coverage to scientific news. It is media's responsibility to educate and aware the masses. Awareness about science and technology is necessary to create a scientific culture and developing knowledge economy and to attain this goal the role of media is inevitable.

\section{Importance of Awareness in masses}

Human society is a bonded community where humans live and interact with each other. Human is a social animal and can't live in isolation. To nurture this basic instinct of mankind there are certain ways to educate and aware them in a manner so that they may live a bonded social life. Danette (2013) narrated that we can define social awareness in two ways. The first way is the indication of knowledge of social acceptance and to act upon what is acceptable in society. The second way about to be aware of different societal problems and to tackle those problems accordingly. Heather (2016) further elaborated that the present age is the age of knowledge and awareness. Because of the modern inventions like cell phone we as a society are now capable to know and carry out any research which we want. Likewise other inventions, yes, the cell phones also have adverse impacts due to heavy use of social media which is largely unregulated but with the help of cell phone we are now able to quickly learn whatever we desire.

\section{Role of media in inculcating awareness among the masses}

The role of media in spreading awareness among masses on social, national and international issues is very crucial. Media had grown rapidly in the present era, which made available multiple forms to get the latest information on each and every matter. Kanika \& Jaspreet (2016) said that the media is moving with the society and reshaping itself and adapting to the changing needs of the society. During the past two decades the media has developed extensively and quickly because of the overall comprehensive development of the society. The arrival of new media has also changed the scenario of media industry while other forms have also continued growing. All these development and changes in media industry is solely due to progress and development of technology in media usage.

\section{Science journalism}

Science journalism conveys reporting about science to the public. The field typically involves interactions between scientists, journalists, and the public.

\section{Significance of Science journalism}

Sumit (2016) stated that presentation of logical reasoning and actualities, facts and figures, ideas and learning in the dialect of news coverage are the core requirements 
of science journalism or science reporting. These core characteristics of science reporting create interest in the masses.

\section{Statement of Problem}

Media has a great role in all spheres of life and play a critical role in socio-economic development.

In modern world all countries try to excel in science and technology as through scientific development the way for economic prosperity paves. Pakistan is a developing country and to strengthen its economy a proper attention is required from the government on scientific development. This will only develop when we construct our society on scientific principles.

Having said that, this study is an endeavor to examine that how prominent dailies of Pakistan give coverage to science and technology in Pakistan?

Researcher has chose five elements of science and technology i.e. Environment/ Climate, Engineering, Medical/Bio Science, Technology and Space science.

\section{Hypotheses}

English newspapers publish more opinion items on science and technology than Urdu newspapers.

\section{LITERATURE REVIEW}

Nity \& Gaurav (2017) elaborated that being a watchdog media is the mirror image of society and it represents the happenings and working of society. Whatever the medium of media is either it print, electronic or new media, the purpose of media to keep inform the masses. As a voice of society media also educate the people and make them aware of the ongoing activities and happenings besides providing entertainment to public. Because of the diverse available media platforms, the thoughts of young generations has stirred largely and also motivated the different sections of society to be more expressive.

Muhammad Nasir (2013) stated that derivation of the term "media" itself means something which carries anything and its basic approach or purpose is to reach masses. The term "media" was coined after the beginning of newspapers, periodicals and magazines and later it was widened by the advent of radio, television and internet. Now media is integral part of our daily life almost an important necessity. There is no doubt that presently our society is heavily dependent on the media and media too playing a significant role in societal development of our society. We get information from media, we use it for education, entertainment and shaping opinions. We do aware of current affairs and happenings of not only or area but about the world because of media. Besides informing, educating, entertaining and agenda setting, media puts strong social and cultural impact on society which can lead to bring positive societal changes. The intrinsic ability of media to reach bigger number of public enables it disseminates messages to construct public opinions and create awareness. 
Siobhan (2012) hinted that the evolution of new technologies in the avenue of media has changed the society and the degree of physical interactions amongst the masses. Technological advances successfully bridging the gap of age, gender and the role of different people in family thus increasing conversations on almost all topics. Newly evolved technologies also increase the requirement of privacy as people want a complete control on such technology to be used upon their own discretion. To ascertain the impacts of social media technologies on the families a research is needed to know whether such technologies strengthening or weakening the bonding of members of a household.

Dr.Zhu \& Dr. Purdam (2017) explicated that social media tools are helping current day scientists and researchers towards provisioning of opportunities for their scientific and research work. Sharing of research data on social media platforms fruits into the public participation towards the same which enhance the interest of masses into the research work outcomes.

Benoit \& Yves (2000) stated that discussion about scientific culture became larger and most practiced in most of the public debates in last ten years. Official views of policy makers now stressed on economic development and social prosperity. In previous few years, policies evolved in OECD (Organization for Economic Cooperation and Development) countries incorporate the culture of science and technology as an aim or goal.

Donald (2010) narrated in his book "Science and the Media" that a general and widespread understanding is very much important for the public and United States of America is not having too much of such understanding. There is no doubt about the curiosity of American people and indeed they have an amazing sense of wonder. We can not undermine the cultural impact of knowledge of sciences particularly natural science and that too with the same level of arts and humanities. The decisions have to be made by the democratic system of the United States of America as there is an array of important technological issues like actions and efforts on climate change, exploration of apace and use of space for socio economic development, devise sustainable and renewable energy plans, latest advancements in medical and biological sciences. To elect suitable political representatives of the country the voters also require a certain understanding of science and technology. For all this, United Stated of America have to establish a firm layer of scientific community consisting on reckonable scientists which will lead the nation through their scientific explorations and discoveries and resultantly will prepare the upcoming generations for new scientific and technological developments Dramatic or stunning research accomplishments do inspire the young generations which will be made by the scientists and scientific authors will write about it to disseminate this in masses.

All the stated aspects are pillars which support scientific culture and the relationship between scientists and science journalists is so more important that the above stated aspects depend on it. To maintain a good relationship, the best reporters have learned a lot about science and technology and the sane scientists have too emphasized the importance of good relations with journalists. Likewise, any other matter, there 
are complaints heard from both sides. For example if a reporter had not enough background knowledge about climate change and subsequently he do a comparison of scientist's views and a person who denies global warming will not be beneficial. Richard (2006) stated that to create and spread awareness in public is basically a way to inculcate the information in society about certain issues and with the help of information the attitudes, beliefs and behaviors of the society are positively influenced so that we may achieve a desired goal.

Jan (2004) said that without media, the progress of science and technology would have been very difficult. The culture, civilization, architecture and art were only passed on to the next generations because of media. Media is also a key player in spreading scientific awareness and also it will continue to pass on these all things to future generations. Let us aside the intrinsic relationship between media and science, as the civilization progressed, the scope and importance of media interaction has been rapidly increased and therefore the impact of media on the progress and development of science has also been changed. Scientists of all fields present their research work through research publications which is the most accepted and practices way of output in research fraternity across the globe. It could be research papers, research journals, monographs and now blogs. The range of these publications is local or international, depending on the level of publication, reputation and type of journals and language. Well, globally the most of the research papers are in English like in psychology, about $95 \%$ of articles and books are published in English. The role of media is evident here but yes there are so many outstanding research achievements which only publish in local journals or in less known languages therefore do not circulate in global science.

Bharvi and Garg (2015) narrated that very less coverage given to science and technology items in English language dailies in the year 1996 which actually amounts less than one percent of the total printed area and even this low coverage was not for all times and it was not regular. 03 newspapers i.e. The Pioneer, The Hindu and The Times of India gave science coverage. Out of the various topics nuclear science and technology, defence, space research and astronomy were given the highest coverage while there was a very least coverage given to ethics in science and technology, science and industry, and science and technology information.

Items related to issues on policy of science and technology in India, given approximately one-fourth of the total coverage. The writers were mostly the top reckoned scientists, academicians, bureaucrats etc. Most of the articles regarding science and technology policy were published by The Times of India, The Economic Times and The Indian Express and their source was mostly from within India. 28 percent of the items related to non-policy topics having their sources from outside India, mainly the UK and USA. The stories with political implications were given the coverage on front page whereas the majority items were placed on the inside pages. The column space and spread of most of the items on the inside pages was enough to grasp the attention. Illustrations were also there to support the almost 53 percent of non-policy items and almost all the items in the field of astronomy had either a picture or a drawing or a sketch. 
Dr.Meenu (2013) revealed in his study that with comparison to other types of information a very little amount of literature on science and technology published in print media of India which makes the average of only 2.04 percent. The efforts for the development and progress of science and technology publishing are so far not successful in India as the country is full of superstitious and false believes and it obscures the way of logical reasoning and scientific culture in the society. Such superstitious and false believes prohibits the people to participate in the development and progress of society and therefore the lag behind in all walks of life. If scientific information is given in attractive and motivating manner, the interest of common men about science and technology will be increased and subsequently they will take active part in the progress and development of nation.

Department of Journalism and Communication, Makerere University (2011) in its UNESCO sponsored research report stated that lack of science and technology issues in African media is because of diverse reasons. The primary reason is that the scientific issues are taken as complex and the local journalists are not capable enough to understand the complex scientific issues as the lack the particular information and ability to cover them. Beside limited capability of African media, there is a little investment made by media to enhance the ability of journalists to make them able to cover science and technology issues.

Hepeng (2007) stated that the science coverage in media is vanishing in China but the situation can be changed by press coordinators, scientists and science journalists. Chinese writers still looks back the era of 1980s and 1990s which were termed as golden period for science journalism in China as presently the science journalism is on the verge of elimination notwithstanding the scientific and technological advancement in China.

M.Hamid (2015) stated that through science journalism we can connect the masses in a vigorous and reliable way, knowing the fact that so many people do not posses scientific background but the topics and issues certainly of their importance. Either we talk about space explorations, climate change, floods, health issues, the science reporters have played a key role in inculcating awareness and shaping the public discourse and opinion. There is no market value of science journalism and very negligible demand as the today's world is infatuated with politics and politicians. During last many years, my interaction was with dozens of reporters and journalists in Pakistan but I could not find a science journalist even I was faced with alarming views from the journalists as they were unaware of the science journalism and can't think about a reporter having interest in meticulous science journalism.

\section{RESEARCH METHODOLOGY}

\section{Procedure}

The present study is designed as purely as quantitative in nature. In this context, the researcher has visited libraries to fetch data from newspapers archives. Publications of year 2017 have been analyzed for data. 


\section{Content Analysis}

Content analysis is a way to count qualitative information by sorting and evaluating the data systematically so that it can be present in a summarized manner. This process includes such methods in which large set of raw data can be converted into useable and presentable data evidences. Therefore Researcher chose content analysis methods, the study examined the content of two different languages leading Pakistani daily newspapers (Daily Dawn (English), Daily Express (Urdu).

\section{Universe}

Publications of Daily Dawn (English) and Daily Express (Urdu) 01st January 2017 to 31st December 2017 have been analyzed. Publications from January 2017 to December 2017 were selected to determine the latest print media trends about the topic.

\section{Sample}

The procedure or modus operandi for selection of an appropriate sample is called "Sampling". Sampling is the selection of certain part of a population which represents the whole population for establishing strictures, distinctiveness and characteristics of the whole population.

The objective of sampling is to illustrate conclusions about populations from samples, inferential statistical tools must be used for determining the characteristics of population by directly examining only a segment or sample of the population.

\section{Sample Design}

It is basically a design or scheme which makes the process easy for the selection of survey sample and put impacts on different important aspects of survey. In an expansive framework, some type of information obtained by interested researchers through a survey for universe or population. The sampling frame which represents the population of interest must be clearly defined. The sampling frame may be the same to the population or it may be only part of it and is consequently subject to some under coverage or it may have an indirect relationship to the population (e. g. the population in college students and the frame is a listing of colleges).

Researcher selects one year of Daily Dawn (English) and Daily Express (Urdu) newspapers from 01st January 2017 to 31st December of 2017 as sample for collection of data and its analysis.

\section{Unit of Analysis}

In this study opinion items published in Daily Dawn and Daily Express in the year 2017 are the unit of analysis.

\section{Data Analysis}

The raw data collected for the study were analyzed with help of software named SPSS. Help was also sorted from MS Excel and MS Word too.

\section{Findings}

The findings of the collected data is presented in below mentioned tables. 


\begin{tabular}{|c|c|c|}
\hline \multirow{2}{*}{ Elements } & \multicolumn{2}{|c|}{ Opinion } \\
\cline { 2 - 3 } & No. & Cm \\
\hline Environment / Climate & 08 & 140.5 \\
\hline Engineering & - & - \\
\hline Medical / Bio Sciences & 05 & 131.5 \\
\hline Technology & 01 & 17 \\
\hline Space science & - & - \\
\hline Total: & 14 & 289 \\
\hline
\end{tabular}

In the year 2017 Daily Dawn published 14 items in whole year. There were 06 editorials on environment and climate published in January, February, June, July, September and November. There were also one article and one letter to editor about environment/climate. In Medical/Bio Science category there were Four editorials and one article published in the months of August, September, October, November and December. In Technology category there was only one letter to editor published in November. There was no item about Engineering and Space science in whole year.

\section{SPSS analysis}

The collected data is further analyzed through SPSS and presented in below table.

\begin{tabular}{|c|c|c|c|c|c|c|}
\hline & EnvrOP & EnggOP & MedBioOP & TechOP & SpaceOP & \\
\hline \multirow{2}{*}{$\mathrm{N}$} & Valid & 6 & 0 & 5 & 1 & 0 \\
\cline { 2 - 7 } & Missing & 5 & 11 & 6 & 10 & 11 \\
\hline Mean & 23.417 & & 26.200 & 17.000 & & \\
\hline Median & 18.250 & & 18.500 & 17.000 & & \\
\hline Mode & $15.0 \mathrm{a}$ & & $12.5 \mathrm{a}$ & 17.0 & & \\
\hline $\begin{array}{c}\text { Std. } \\
\text { Deviation }\end{array}$ & 11.6078 & & 17.9569 & & & \\
\hline $\begin{array}{c}\text { Variance } \\
\text { Mayyyyy}\end{array}$ & 134.742 & & 322.450 & & & \\
\hline
\end{tabular}




\begin{tabular}{|c|c|c|c|c|c|l|}
\hline Range & 31.0 & & 43.0 & .0 & & \\
\hline Minimum & 15.0 & & 12.5 & 17.0 & & \\
\hline Maximum & 46.0 & & 55.5 & 17.0 & & \\
\hline Sum & 140.5 & & 131.0 & 17.0 & & \\
\hline
\end{tabular}

Researcher analyzed the whole year of 2017 data by SPSS. Researcher used nine statistical tools (Mean, Mode, Median, Range, Variance, Standard Deviation, Minimum, Maximum and Sum). According to SPSS result, Opinion category of Environment has total 06 publication months in the year 2017 so the Mean 23.417, Median 18.250, Mode and Minimum 15, Standard Deviation 11.6078, Variance 134.742, Range 31.0, Maximum 46 and sum is 140.5. Second Category of Opinion is Engineering, there was no opinion in this category in the whole year of 2017. The third Category of Opinion is Medical/Bio Science, there was total 05 publication months in the year 2017 so the Mean 26.200, Median 18.500, Mode and Minimum 12.5, Standard Deviation 17.9569, Variance 322.450, Range 43.0, Maximum 55.5 and sum is 131.0. The fourth opinion category is Technology and there was only one month of publication in year 2017 so value 17.00 of every statistical tool except Standard Deviation, Variance and Range. The fifth variable of Opinion is Space science and there was no publication in the year 2017. There were 06 months of publications of Special Editions in year 2017. The Mean 865.833, Median 550.000, Mode and Minimum 270, Standard Deviation 847.4103, Variance 718104.167, Range 2230, Minimum 270, Maximum 2500 and sum is 5195.

Graphical analysis (Daily Dawn (2017))

\section{Opinion No.}

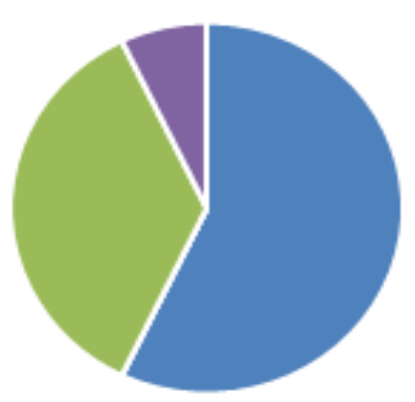

- Environment / Climate - Engineering
- Technology 


\begin{tabular}{|c|c|c|}
\hline \multirow{2}{*}{ Elements } & \multicolumn{2}{|c|}{ Daily Express (2017) } \\
\cline { 2 - 3 } & No. & Cm \\
\cline { 2 - 3 } & 26 & 923 \\
\hline Environment / Climate & - & - \\
\hline Engineering & - & - \\
\hline Medical / Bio Sciences & 07 & 435 \\
\hline Technology & 02 & 63 \\
\hline Space science & 35 & 1421 \\
\hline Total: & & \multicolumn{2}{|c|}{} \\
\hline
\end{tabular}

In the year 2017 Daily Express published 35 opinion items in whole year. There were 09 editorials on environment and climate published in June, July, October and November. There were 16 articles and one letter to editor about environment/ climate. In Technology category there was only one editorial published in the month of October and 06 articles in the months of June, July, September and November. In Space science category there were two articles published in October. There was no item about Engineering and Medical/Bio science in whole year.

\begin{tabular}{|c|c|c|c|c|c|c|}
\hline \multicolumn{7}{|c|}{ SPSS analysis } \\
\hline \multirow{2}{*}{$\mathrm{N}$} & EnvrOP & EnggOP & MedBioOP & TechOP & SpaceOP & \\
\hline \multirow{2}{*}{$\mathrm{N}$} & Valid & 7 & 0 & 0 & 5 & 1 \\
\cline { 2 - 8 } & Missing & 5 & 12 & 12 & 7 & 11 \\
\hline \multicolumn{2}{|c|}{ Mean } & 131.857 & & & 87.000 & 63.000 \\
\hline \multicolumn{2}{|c|}{ Median } & 114.000 & & & 91.000 & 63.000 \\
\hline \multicolumn{2}{|c|}{ Mode } & $16.0 \mathrm{a}$ & & & $56.0 \mathrm{a}$ & 63.0 \\
\hline \multicolumn{2}{|c|}{ Std. Deviation } & 127.5744 & & & 28.1603 & \\
\hline \multicolumn{2}{|c|}{ Variance } & 16275.226 & & & 793.000 & \\
\hline
\end{tabular}




\begin{tabular}{|c|c|l|l|l|l|}
\hline Range & 352.0 & & & 60.0 & .0 \\
\hline Minimum & 16.0 & & & 56.0 & 63.0 \\
\hline Maximum & 368.0 & & & 116.0 & 63.0 \\
\hline Sum & 923.0 & & & 435.0 & 63.0 \\
\hline
\end{tabular}

Researcher analyzed the whole year of 2017 data by SPSS. Opinion category of Environment has total 07 publication months in the year 2017 so the Mean131.857, Median 114.000, Mode and Minimum 16.0, Standard Deviation 127.5744, Variance 16275.226, Range 352.0, Maximum 368.0 and sum is 923.0. Second Category of Opinion is Engineering, there was no opinion in this category in the whole year of 2017. The third Category of Opinion is Medical/Bio Science and therewas no opinion in this category in year 2017. The fourth opinion category is Technology and there has total 05 publication months in the year 2017 so the Mean 87.000, Median 91.000, Mode and Minimum 56.0, Standard Deviation 28.1603, Variance 793.000, Range 60.0, Maximum 116.0 and sum is 435.0. The fifth variable of Opinion is Space science and there was only one month of publication in year 2017 so value 63.00 of every statistical tool except Standard Deviation, Variance and Range.

\section{Opinion No.}

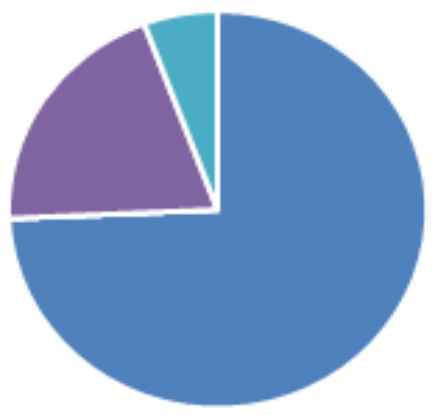

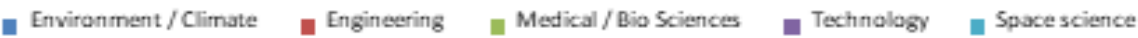




\section{CONCLUSIONS \& RECOMMENDATIONS}

The collected data has revealed that Urdu newspaper i.e. Daily Express has given extensive coverage to science and technology. And having a credible reputation and being top English daily "Daily Dawn" has not given proper coverage to science and technology and hence the role of such an influential newspaper for inculcating awareness is not achieved. In the light of collected data the hypotheses is disapproved. It is recommended that more coverage should be given to science \& technology in English dailies to spread scientific awareness among the masses.

- Regular publication of science editions (weekly) is suggested.

- Pakistan is an agriculture based country and majority of the population lives in rural areas. Urdu newspapers are suggested to publish items about latest agriculture technology and trends to aware the farmer fraternity of the country.

- Daily Dawn is suggested to give extensive coverage to science \& technology so that the goal of building knowledge economy may be achieved.

- To get the attention of policy makers, more editorials may be published about science \& technology and new ways may please be advised to policy makers and government for creating scientific culture in the society.

- It is suggested that scientists and engineers may please be encouraged to write opinions so that they can present their point of view and rationale.

- Print media organizations (newspapers) are suggested to arrange training of science journalism for their reporters/journalists through local/foreign experts.

\section{REFERENCES}

Burke. J, Bergman. J \& Asimov. I (1985). The Impact of Science on Society. NASA Langley Research Centre, USA.

Department of Journalism and Communication, Makerere University (2011), Research Report on Media Coverage of Science \& Technology in Africa (sponsored by UNESCO). Kampala, Uganda.

Dr. Kumar. M (2013), Comparison of Science Coverage In Hindi and English Newspapers of India: A Content Analysis Approach, Global Media Journal - Indian Edition/ISSN 2249-5835 Sponsored by the University of Calcutta/ www.caluniv.ac.in Summer Issue / June 2013/ Vol.4/No.1

Dutt. B \& Garg. K.C (2000), An overview of science and technology coverage in Indian English-language dailies, IOP Publishing Ltd and The Science Museum.

Dr. Y. Zhu \& Dr. K. Purdam (2017), Social Media, Science Communication and Academic Super Users in the UK.

Francis. H (2016). The Importance of Awareness. Odyssey Magazine.

Godin. B \& Gingras. Y (2000), What is scientific and technological culture and how is it measured? A multidimensional model. Public Understand. Sci. 9 (2000) 43-58. United Kingdom

Jia. H (2007), The crisis in China's science journalism, Sci Dev Net, Bringing science \& development together through news \& analysis.

Kennedy. D(2010), Science and the Media, American Academy of Arts and Science. Kanika \& Kaur. J (2016) Media As An Agent for Inculcating Values: A Truth or A Myth, Volume 7, International Journal of Educational Research and Technology, 
India.

McGrath. S (2012), The Impact of New Media Technologies on Social Interaction in the Household, Department of Sociology, National University of Ireland Maynooth.

Narula. S (2016). The Significance and Convenience of Science Journalism, Journal of Mass Communication, Amity University, India.

Nasir. W (2012). The Impact of Science on Society. Daily The Nation, Lahore, Pakistan.

Nasir. M (2013), Role of Media in a Developed Society, Sarhad University of Science \& Information Technology, Peshawar, Pakistan, Interdisciplinary Journal of contemporary Research in Business.

Pew Research Centre (1999). Scientific Inventions and Social Trends. Technology Triumphs, Morality Falters, Washington DC, USA.

Pandey. N \& Singh. G (2017). Role and Impact of Media on Society: A Sociological Approach with Respect to Demonetization, International Journal of Research on Humanities, Arts \& Literature. Ambedkar University, India.

Sayers. R (2006), Principles of Awareness-Raising for Information Literacy. UNESDOC Digital Library. Bangkok, Thailand.

Swanepoel. D (2013). The Importance of Social Awareness. Pro Fusion Magazine, South Africa.

Strelau. J (2004), Science and Media, Article in: ALLEA Biennial Yearbook 2004. Critical Topics in Science and Scholarschip (pp.91-98). Amsterdam: ALLEA

Zaman. M.H (2015), The Missing Genre, The Express Tribune, https://tribune.com. $\mathrm{pk} /$ story/880805/the-missing-genre/ 